\title{
'FACTS' AND 'STATEMENTS OF FACT'
}

\author{
WAITER WheELER CoOK*
}

7 HE CIVIL Practice Act recently adopted in Illinois contains one section which in its wording deliberately departs from the language commonly used in codes of civil procedure. This is section 33, which provides that

All pleadings shall contain a plain and concise statement of the pleader's cause of action, counterclaim, defense, or reply.

This language is similar to that of the corresponding section of the New York Civil Practice Act, but differs-and this is the interesting point -in that all reference to 'facts' is omitted. To bring out the difference it will be helpful to quote the section of the New York Act, italicizing the part which refers to 'facts.' The New York provision reads:

SECTION 24r. Every pleading shall contain a plain and concise statement of the material facts, without unnecessary repetition, on which the party pleading relies, but not the evidence.

Order r9, rule 4 of the English rules governing the matter contains similar language. It reads:

Every pleading shall contain, and contain only, a statement in summary form of the material facts upon which a party pleading relies for his claim or defense, as the case may be, but not the evidence by which they are proved.

For the purpose of simplifying our discussion let us concentrate our attention upon the complaint. The New York and the English law is that the plaintiff must state the "material facts"; the Hllinois provision is merely that he must give a plain and concise "statement of the cause of action."

This departure from the traditional language of the codes, we are told by the late Professor Edward W. Hinton, who was in a position to know, was intentional and done for a purpose. The explanation which Professor Hinton gives is as follows:

The Committee .... decided to omit the word "facts" in order to minimize so far as possible the controversy that has arisen in so many code states where pleadings have been constantly attacked as setting out conclusions rather than facts. ${ }^{x}$

* Professor of Law, Northwestern University School of Law.

× Hinton, Stenographic Report of Lectures on Illinois Civil Practice Act 6 (I934). 
In explanation of the action of the Committee Professor Hinton goes on to say:

All the earlier writers on Code Pleading emphasized that the new system was a fact system and that the pleader was to state facts, the whole facts, and nothing but the facts, and that has led to a great deal of useless controversy. No pleading was ever formulated that stated facts and nothing but facts. It is impracticable if not impossible to make a pure fact statement. The common-law system with which you are familiar made practically no attempt to require the statement of facts. Just consider for a moment. The common count in assumpsit alleged that the defendant was indebted to the plaintiff for goods, wares, and merchandise sold [and] delivered to him, and, being so indebted, in consideration thereof undertook and promised to pay-not a single fact. Absolutely not a single fact. What, in point of law, creates a debt? It is not stated. What, in point of law, constitutes a delivery? It is not stated. What, in point of law, constitutes a promise? It is not stated. The pleader simply states the legal result of unstated facts. Those are the common counts in assumpsit."

If we ask whether this omission of the words "material facts" from the Illinois Act has prevented the same doubts and difficulties from arising as arose under earlier codes, the answer seems to be that it has not done so. For example, we find Professor Hinton and Professor O. L. McCaskill, both of whom were consulted in the drafting of the Illinois Act, ${ }^{3}$ disagreeing as to just what the pleader is required to do. In Professor Hinton's lectures from which we have quoted above we find several pages devoted to speculation as to what meaning the Illinois courts may give to the provision under discussion. How shall a pleader 'state' the 'cause of action'? Must he state 'facts'? Professor McCaskill's answer is that he must. He says:

A plain and concise statement of the pleader's cause of action, counterclaim, defense, or reply, as provided for in this section, is a statement of the ultimate and issuable facts essential to a good cause of action, defense, or reply. The substance of good pleading, as it has heretofore been understood in this state, is retained without change.....

.... A cause of action must be stated. It will be noted that the requirement is not that the nature of the claim only be stated..... The statement of a cause of action involves a statement of the essential fact elements of which it consists. ${ }^{4}$

Another Illinois teacher of pleading expressed orally to the present writer the same view. His argument was substantially as follows:

I Ibid.

3 It should be noted that Professor Hinton was not the draftsman of the act. Professor Edson R. Sunderland was employed to prepare the original draft, and Professor McCaskill was officially made technical consultant of the committee in charge. Professor Hinton was one of many members of the bar whose advice was asked and given.

4 McCaskill, Ill. Civ. Prac. Act. Ann. 64-67 (1933). 
The complaint must state a cause of action; a cause of action consists of facts to which the law attaches the legal consequences of liability; therefore the facts constituting the cause of action must be stated, otherwise the pleading does not state the cause of action.

All of which seems quite clear until we read what Professor Hinton, a great master of pleading, has to say. If the reader will re-examine the passage from his lectures quoted above he will see that we are told that the 'common counts' as we had them at common law state "not a single fact." But, the reader may say, perhaps the common counts are not permissible under the Illinois Act. On this point we have Professor Hinton's own testimony. He tells us:

At the time the committee were engaged in preparing this act they had some doubt whether the common counts would still be good. I don't think there is any serious doubt on that point. I cannot find any provision in the Act that would abolish the common counts, and we find them in full use and operation under the standard code and also under the New York Civil Practice Act and the New Jersey Practice Act, and in fact under the English rules they are still using the common counts. So I, with all deference to some of the members of the committee that had some doubts on the subject-I do not think there is any serious question but that the common counts will be just as available under this Practice Act as they ever were. It would be most unfortunate if the common counts were eliminated. They are too convenient. They cover too many cases of variance and permit a recovery where otherwise the plaintiff would fail.s

It would thus seem that Professor Hinton's view was that a complaint will be good under the Illinois Act if it states "not a single fact," but merely "the legal result of unstated facts." Let us now turn again to Professor McCaskill's annotations to the Illinois Act and see what we find. He says:

The common counts in debt and assumpsit are a close approach to notice pleading. About all they do is give notice of the general nature of the claim, without giving any notice of the real issues to be tried. .... . The use of the common counts violated the spirit of a "plain and concise statement" [of the facts]. . . . Whatever the interpretation of the Code section [as found in New York and other states and in England] it would seem that the common counts have no place under the Civil Practice Act. ${ }^{6}$

Thus the experts disagree. It is proposed in the present discussion to ask why this is so, and how it comes about that a statute so carefully drafted as the Illinois Civil Practice Act gives rise to such fundamental differences of opinion on the part of those who, being expert in the field, ought to know. Is there a deficiency of skill in draftsmanship, or what is the source of the difficulty? Why is it that apparently the omission of the

5 Hinton, op. cit. supra note 1 , at $\mathrm{I}_{4}$.

${ }^{6} \mathrm{McC}$ askill, $o p$. cit. sulpra note 4, at 69 . "Notice pleading requires only the setting forth of the nature of the demand or defense, omitting elements essential to the cause of action." Id. at 67 . 
word 'facts' from the Illinois Act has apparently had small effect in preventing the kind of controversies which have raged under the ordinary code provisions which retain that word? It is to the solution of this problem that the remainder of this paper will be directed. ${ }^{7}$ It is hoped to demonstrate what the source of the difficulty is and thereby to point the way which if followed by other drafting committees and legislative bodies will prevent a recurrence of the type of controversy under consideration. The aim of the present paper is therefore severely practical. Unfortunately, the problem can not be solved-or at least so the present writer believeswithout making an excursion into a field of discussion which, it is feared, is anathema to the average member of the legal profession. That is to say, we shall have to consider certain matters usually relegated to that curious and supposedly useless study known as 'philosophy.' The reference is, however, not to philosophy in the sense of metaphysical discussion of the ultimate nature of the universe-in that we are not here interested. The reference is rather to an examination of such fundamental matters as the meaning of words and how words get their meaning, and similar problems. What, for example, is the meaning of the word 'facts,' and what of the words 'statements of fact'? Our problem thus reduces itself to this: What do the words 'facts' and 'statements of fact' mean? Let us begin with 'facts.' 'Facts,' we are told, are just what they are, they exist. Here it will be useful to recall to mind a well-known statement found in a leading text-book on code pleading. This writer tells us:

The issuable facts [in an action or suit] should not only be stated to the complete exclusion of the law and the evidence, but they should be alleged as they actually existed or occurred. . . . The allegations must be of dry, naked, actual facts. ${ }^{8}$

7 The present writer outlined what he believed to be a solution of the problem in an earlier paper: Statements of Fact in Pleading under the Codes, 2I Col. L. Rev. 4I6 (I92r). Further consideration has convinced him that the point of view there expressed was essentially sound, but that the matter can be expressed more clearly: hence the present paper. An additional reason for attempting to restate the conclusions reached in the earlier paper, as well as the argument in their support, is that some writers have failed to interpret the earlier paper correctly. See Gavit, Legal Conclusions, 9 Ind. L. J. Iog (I933). Doubtless this was more the fault of the present writer than of his critics. See note 17 infra.

${ }^{8}$ Pomeroy, Code Remedies 560, 56I (4th ed. I904). The complete text of the passage reads as follows: "The issuable facts in a legal action, and the facts material to the relief in an equitable suit, should not only be stated to the complete exclusion of the law and the evidence, but they should be alleged as they actually existed or occurred, and not their legal effect, force, or operation. This conclusion follows as an evident corollary from the doctrine that the rules of law and the legal rights and duties of the parties are to be assumed, while the facts only which call these rules into operation, and are the occasion of the rights and duties, are to be spread upon the record. Every attempt to combine fact and law, to give the facts a legal coloring and aspect, to present them in their legal bearing upon the issues rather than in their actual naked simplicity, is so far forth an averment of law instead of fact, and is a direct violation of the principle upon 
Note that underlying this passage are two assumptions: (a) the 'facts' existed or occurred; (b) they can be "alleged," i.e., 'stated' in language which will describe them "as they actually existed or occurred." The eminent author of the passage quoted is not alone in this belief; it is shared by men in other walks of life, even by scientists of reputation. Thus we find a professor of chemistry in one of our large universities telling us that

the fundamental facts of chemistry will still be valid at the end of the next half century. Of course that must be, for facts, defined as "the direct result of observation, unmodified by any act of reason," are eternal.9

If we ask how much sense and how much non-sense such statements make, we shall discover first of all that all those who make such statements are assuming - as indeed do all scientists the present writer happens to know-that there is an external world of 'fact,' and that we must take due account of these external 'facts' if we wish to continue to exist and be more or less comfortable. On this much all are agreed. It is in this sense of the word 'fact' that we can say that 'facts' are coercive; that they exist independently of our will; that they are "compelling elements of common-sense experience, a careful adjustment to which is the necessary condition of successful, or even continued living." "10

Suppose now that we wish to make some 'statement' about these 'facts': can we describe them as they "actually exist or occur," that is,

which the codes have constructed their system of pleading. The peculiar method which prevailed at the common law has been fully described; it was undoubtedly followed more strictly and completely in certain forms of action than in others; in a few instances-as in a special action on the case-the declaration was framed in substantial conformity with the reformed theory. But in very many actions, and those in constant use, the averments were almost entirely of legal conclusions rather than of actual facts. The familiar allegations that the plaintiff had 'bargained and sold' or 'sold and delivered,' that the defendant 'was indebted to the plaintiff,' or 'had and received money to the plaintiff's use' and frequently even the averment of a promise made by the defendant, may be taken as familiar illustrations from among a great number of other similar phrases which were found in the ordinary declarations. Rejecting as it does the technicalities, the fictions, the prescribed formulas, and the absurd repetitions and redundancies of the ancient common-law system, the new pleading radically differs from the old in no feature more important and essential than this, that the allegations must be of dry, naked, actual facts, while the rales of law applicable thereto, and the legal rights and duties arising therefrom, must be left entirely to the courts. While this doctrine has been uniformly recognized as correct when thus stated in an abstract and general manner, it has sometimes been overlooked or disregarded in passing upon the sufficiency and regularity of particular pleadings." (Italics added.)

9 Cady, The Chemistry of the Future, 66 Science I (1927).

${ }^{10}$ Barry, The Scientific Habit of Thought 92 (1927). Barry adds: "No one doubts that there are coercive factors in general experience which certainly determine action, and also in some degree determine thought and will, though to an extent which is disputable. These existences, science, like common sense, calls facts." 
as "dry, naked, actual facts"? The writers quoted, pleader and scientist alike, obviously assume that we can. And that, the present writer is convinced, is not only an erroneous assumption; it is philosophical and scientific non-sense which ignores the difficulties involved in the use of language and in the determination of what you are going to say the 'facts' are. Upon another occasion, when discussing the problem orally before a bar association, I ventured to suggest that had the framers of the Code, had the judges who construed it, had the legal profession generally, realized this, much useless litigation might have been avoided and large sums of money saved both for clients and for the community. ${ }^{\text {II }}$

Let us examine into the matter. When we look at this 'external world' of coercive 'facts', with what are we presented? Here it is difficult to talk at all without saying more, and also less, than one is justified in doing, and so one runs the risk of serious misinterpretation. Nevertheless the risk must be taken. Without attempting precise analysis - that is unnecessary for our present purposes-we can at least say that what is "out there" in the external world presents itself to us as a shifting, varying series of changing patterns of color, sound, odor, and what not. We may with C.I. Lewis ${ }^{12}$ call this the "given," meaning thereby the element in all experience which we are aware we do not create by thinking and can not in general displace and alter. Or, as the present writer expressed the matter upon another occasion, we may call this the "brute fact element" in experience, or perhaps "brute, raw events." ${ }_{33}$ If we try to describe this "given," these "brute, raw events," we discover first of all that there are an infinite number of aspects in any 'situation,' and that in order to talk about it at all we have to select from among these infinitely varied aspects those which for some reason or other we are going to talk about. In the second place we discover that in talking about the selected aspects we have to relate them in such a way as to put them under some category, some class, for which we have (or perhaps create) a verbal symbol or name. If for example I say that I have in my hand a fountain pen, I have selected from the variety of colors, shapes, etc. now presented to me a particular combination, and I have related these selected aspects so as to place them into the class of 'objects' ${ }^{\text {' }}$ represented by the verbal symbol 'fountain pen.'

${ }^{x} 5$ Lectures on Legal Topics 369 (r928).

12 Lewis, Mind and the World Order 49-50 (I929).

13 For a more detailed analysis of the "given," see the paper on The Possibilities of Social Study as a Science, Essays on Research in the Social Sciences 27, 33 (r93r).

${ }^{14}$ On the meaning of 'object,' see Bridgman, The Logic of Modern Physics 33-36 and 9I-94 (r927); Whitehead, The Concept of Nature I $_{43}$ (r926). 
In other words, in making a 'statement of fact' about the 'given' situation (series of events), so as to state 'what it is,' I have in every case necessarily selected certain aspects, thereby neglecting all the other possible aspects which I might have observed, and then have interpreted the selected 'data' - to use a scientific term-so as to bring them under some category. Then and only then can I say 'what it is,' that is, make a 'statement of fact.' Apparently all 'statements of fact' are the result of a process of this sort, and are not the "direct result of observation, unmodified by any act of reason" as the professor of chemistry quoted above seemed to think. ${ }^{15}$ This will become clear if we examine any book on chemistry. We find that the 'facts' described do not accord with the 'given,' the 'brute, raw event' out there 'as it is' in any absolute sense. They are the product first of 'abstraction' from the concreteness of the 'given,' and then of interpretation of the elements abstracted: see the illustrations given at a later point in this discussion.

Next to be noted is that what our observer 'abstracts' from the 'given' will depend upon his past experience and education as well as upon the purpose he has in view at the time. As his fund of experience widens and also as his purpose changes he will select different combinations of aspects and relate them in different ways.

All this is itself abstract. Let us be more concrete by noting one or two examples from the field of chemistry which will perhaps enable the reader to see more clearly what we are saying. A few years ago if one had looked into the books on that subject he would have found a 'statement of fact' about lead, to the effect that its "equivalent weight" was I03.6. Today he would be told that samples of lead from different sources may have different equivalent weights, although apparently in all other respects they are alike. This is expressed by saying that there are "isotopes" of lead of differing weights. What has happened is that as experience has widened, partly because improved methods of measurement have been devised, the chemists have developed theories and hypotheses about the atomic structure of matter which have led them to select aspects of the situation previously neglected and to interpret them in the manner stated.

is For further discussion of this point, see the writer's paper on The Legal Method, Proceedings of Fifth Conference of Teachers of International Law 50 (x933).

Immediately after birth the new-born organism is of necessity constantly responding to a 'selection' from the infinitely varied 'stimuli' furnished by the 'environment.' Perhaps we might call this process "physiological induction." (Cf. Bertrand Russell, Philosophy 79 (I927)). Even later when we have 'rationalized' the process as 'scientific' or 'logical induction' most of our 'selecting' and 'interpreting' goes on rapidly by means of acquired habits. The result is that most of the time we do not have to 'think,' and so acquire the illusion that we are directly observing "facts" as they are, "unmodified by any act of reason.". 
The chemistry books of a few years ago also told us that 'water' was a homogeneous substance, a compound of two atoms of hydrogen and one of oxygen. At that time all hydrogen atoms were supposed to have an equivalent weight of approximately $\mathbf{I}$, and oxygen atoms an equivalent weight of I6. With the 'discovery' of the 'fact' that a given element might have varying equivalent weights and with the development of chemical theory, the scientists were led to the belief that there might be 'hydrogen' with a weight of 2 , and also of 3 ; also that there might be 'isotopes' of oxygen. Thus it comes about that to-day the 'fundamental facts' of chemistry - but not as unmodified by any act of reason-are stated to be that a glass of 'water' may contain ( $\mathrm{I}$ ) a very large proportion of ordinary $\mathrm{H}_{2} \mathrm{O}$; (2) a much smaller proportion of $\mathrm{D}_{2} \mathrm{O}$ (that is, of oxygen combined with 'hydrogen' of weight 2, now called "deuterium" and symbolized by $\mathrm{D}$ ); (3) of a still smaller proportion of $\mathrm{T}_{2} \mathrm{O}$ (that is, of oxygen combined with 'hydrogen' of weight 3 , now called "tritium" and denoted by $\mathrm{T}$ ); and (4) a varying number of molecules composed either of $\mathrm{H}, \mathrm{D}$, or $\mathrm{T}$ but having oxygen of an equivalent weight of $I 7$ or $I 8$ instead of $I 6 .^{16}$

To be emphasized is that the assumptions with which the observer approaches a given situation, assumptions which are derived from previous interpretations of selected data made by himself and others, will determine even more than his eyesight 'what' he sees, i.e., what aspects he selects as his 'data' and what interpretation he gives to them after they have been selected. It is just this which makes the difference between a Sherlock Holmes and a Watson; between a good medical diagnostician and a poor one; between a good lawyer and a poor one. An example which will illustrate this is found in the case of a small girl who had been advanced to the third grade by tender-hearted teachers even though she had thus far shown an inability to learn to read even such simple words as 'house.' Physicians and other 'experts' who examined her had concluded that the case was hopeless and that probably there were physical lesions in the 'cortical association tracts' which would prevent her from ever acquiring an ability to read. Fortunately for the little girl in question a psychologist trained under Alfred Adler happened to have his attention called to the case. He approached the problem with the hypothesis which Dr. Adler had formulated that difficulty in learning to read is often associated with left-handedness, and that this is even more likely to be the case if the child is a "converted sinistral," i.e., one who, naturally left-handed, has been compelled to use the right. hand. Sure enough, the girl in question was a converted sinistral, and by following a simple technique the psy-

${ }^{16}$ For other helpful examples see Barry, op. cit. sutpra note io, at $370 \mathrm{ff}$. 
chologist in question taught the child in a few months to read better than anyone else in her class. Note the process: The assumption in question led the psychologist to select from the given situation aspects which the other experts had not noticed, or perhaps discarded as of no importance, and to interpret them in a manner which led to a solution of the difficulty, inability to learn to read.

The foregoing is an exceedingly brief and in many ways a crude statement of a difficult and complex matter, and very likely open to misinterpretation. It is hoped, however, that it will serve the purpose of the present discussion. That purpose is to point out that in order to state the 'facts' of a given situation a pleader must first select from the infinite number of aspects of the 'given'-the 'crude, raw events'-those which he deems to be of importance, that is to say, 'relevant' to the purpose in hand, which is to inform the court and the other party of the grounds upon which he claims the court ought to intervene in his behalf. Having made his selection he must relate the selected 'data,' i.e., interpret them, by putting them into categories, i.e., under certain verbal symbols. As he is a lawyer, it will not be surprising if before he is through he uses verbal symbols which have for lawyers acquired a technical significance. Here he proceeds exactly as would a chemist or a physician or the member of any learned profession. Ignoring for the moment this latter aspect of the lawyer's attempt to state to the court and the other party the grounds of his claim, let us note another source of difficulty. To see just what this is it may be helpful once again to leave the field of law and discuss a simple situation in everyday life.

Suppose I am looking out of the window of the room in which you and I are and you ask me: "What do you see?" Any reply I make, assuming I see 'something,' will be a 'statement of fact.' Suppose my reply is: "I see an object": this tells you something but not much; nevertheless it is a 'statement of fact.' Perhaps you ask for a more detailed statement. I reply: "I see an inorganic object." You now know more than before, but perhaps you are still not satisfied, and my next reply may be: "I see a vehicle." This is equally a 'statement of fact,' as will be a statement that "I see an automobile." I may under your urging go on to more and more detailed statements, such as: "I see a five passenger sedan;" "I see a 1935 Ford four-door sedan, with blue body and black wheels"; and so on. Each statement becomes more and more detailed, tells you more and more about what you could see if you were to look. ${ }^{17}$

${ }^{27}$ In the paper by Professor Gavit referred to in note 7 supra, the present writer is quoted as asserting (in his paper in 2I Columbia Law Review) a series of propositions about the matter which he really never did assert. Thus he is charged with saying that there is "no logical dis- 
Suppose now the only directions you were to give me when you asked me to look out of the window and tell you what I saw were that I was to 'state in plain and concise language the facts' of the situation outside the window, or at least of that part of it in which I was interested; or suppose, to adopt language like that of the Illinois Civil Practice Act, you told me to 'state what you see in plain and concise language.' Is it not clear that anyone of the answers given above would prima facie comply with these directions, and that none of these answers would be an adequate guide to me as to what you wished to know? There seems only one answer to this, namely, that I would be completely at a loss as to how general or how specific you desired my statement to be.

In other words, a direction to 'state the facts' of a situation or to 'describe the situation' is an inadequate guide without more. The matter will, to be sure, be helped if I know for what purpose my answer is to be used, and of course that is the case in pleading: the pleader's statement is for the purpose of informing the court and the other party of the grounds upon which the pleader asks action in favor of his client. Even so our difficulties are not over. How much of the 'concrete particularity' of the given situation ${ }^{x 8}$ shall the pleader tell the court and the other party? The language of the English order, of the New York Civil Practice Act, and of the Illinois Civil Practice Act are silent on the point. If we say by way of explanation: "Tell enough fairly to apprise the court and the other party of the issues," there is still plenty of opportunity for doubt as to what is required.

At this point we may with profit recur to the fact that a lawyer-as distinguished, let us say, from a chemist - will use lawyer's words in stating his 'facts,' that is, in interpreting the selected 'data' by putting them into categories. His categories will be legal categories, not chemical. An

tinction between evidentiary and operative facts" when all he intended to say, and thinks he did say, was that in some cases a pleader had been charged by a court with pleading 'evidentiary facts' when all he had done was to plead the 'operative facts' with too great particularity. A reference to $2 \mathrm{I}$ Col. L. Rev. $4 \mathrm{Ig}$ will show that it is specifically pointed out that "at times a pleader does err by 'pleading evidence,' i.e., by stating, generically or specifically, facts which do not form a part of the group of operative facts, but are merely facts from which by some process of logical inference the existence of the operative facts can be inferred": surely a clear recognition of a difference between 'evidentiary' and 'operative' facts. And so for a number of other accusations made by Professor Gavit, the present writer also pleads "not guilty" and refers the interested reader to his original paper. As already suggested, it is entirely probable that certain infelicities of expression in the original paper are responsible for what are obviously wholly unintentional misinterpretations.

${ }^{18}$ This should not be misunderstood. It is not possible to make 'a statement of fact' which will state 'concrete facts.' Every statement will necessarily involve the process outlined in the text. Cf. Ritchie, Scientific Method I55-66 (I923). 
examination of any pleading ever drawn will show that this is precisely what every pleader does. Consider the following approved forms found in the official Connecticut form book. They read:

\section{FOR CONVERSION OF GOODS}

I. On October Ist, I878, the defendant had in his possession ten barrels of flour, worth six dollars a barrel, belonging to the plaintiff.

2. On said day the defendant sold the said flour, without authority from the plaintiff, and thereby converted the same to his own use.

The plaintiff claims $\$ 80$ damages.

\section{ORDINARY TRESPASS DE BONIS}

I. On May 2oth, r879, the plaintiff was lawfully possessed of ten chairs.

2. On said day the defendant forcibly took said chairs from the possession of the plaintiff and carried them away.

The plaintiff claims $\$$ Io damages. ${ }^{x}$

Note the technical legal terms: 'Possession'; 'belonging to the plaintiff'; 'authority'; 'sold'; 'converted'; 'lawfully possessed'; 'forcibly took'; 'carried away.' Obviously only a legally trained person can tell what is meant. It may be asked: "Are these statements which are proper in Connecticut 'statements of fact' or are they merely 'conclusions of law' ?" The answer obviously is that they are both. The statement that the plaintiff was 'lawfully possessed' of the goods in question is very properly interpreted as an assertion that some one of a large number of shifting and varying groups of factual events had taken place, the net legal consequence of which was that the plaintiff was 'lawfully possessed' of the goods. Any one of a large number of combinations of events will, of course, result in conferring 'possession'-as distinguished from mere physical custody-upon a person. Proof of any such combination of events will be proof of the 'possession.' The approved form of statement thus leaves out much of the 'concrete particularity' of the events 'as they occurred.' Any statement will necessarily do that. The only question is, has the statement left out so much that it is not sufficient fairly to apprise court and counsel on the other side of what the plaintiff expects to rely upon?

At this point we come to the crux of the matter. How much is enough? Obviously, the codes as formulated, either in New York or Tllinois, give no answer to that: as many answers might be given as there are persons who attempt an answer, were it not for one thing, namely, past habits and

x9 These forms are taken from The Connecticut Practice Book of r934, forms 252, 266. 
practices of the legal profession, in Tllinois and in other states. ${ }^{20}$ Small wonder that in England, in New York, and in other code. states chaos reigned after the adoption of the "simplified procedure." The ancient landmarks had been swept away and no new ones had been put in their place. Connecticut, be it noted, escaped this confusion and chaos by a very simple expedient: it offered the profession along with the vague provisions of the code a set of officially approved but not required forms for all the ordinary actions. It thus erected new landmarks in place of the old and the Connecticut practitioner did not lose his way in a war of words over what was and what was not a 'statement of fact' and what a 'mere conclusion of law,' one being permitted and the other not.

If the foregoing analysis is accepted, we must conclude that the timehonored distinction between 'statements of fact' and 'conclusions of law' is merely one of degree, comparable to the difference between saying: "I see an object" and "I see a sedan" in the example given above.

In the early part of this discussion the question of the propriety of using the 'common counts' under the Tllinois Act was discussed. One expert took one view; another the opposite view. In the light of the analysis here presented let us restate the problem, which is: Do they tell court and opposing counsel enough? They certainly are 'statements of fact'; the only question is, are they too general? Do they leave out too much of the 'concreteness' of the 'given situation'? A glance at the Connecticut official form book shows that the framers of that code thought not; there is an express provision permitting them "where any of these counts is a general statement of the cause of action." ${ }_{2 x}$ Note how the draftsmen of the Connecticut code recognized that any one of these counts might in an appropriate case be regarded as "a general statement of the cause of action." Of course due provision was made, as at common law, for the filing of a "bill of particulars" where that seemed to be desirable.

On the other hand, it may be argued that a form of complaint which, as in the common law common count in assumpsit for goods sold and delivered, merely alleges that the defendant was indebted to plaintiff in a certain amount for goods sold and delivered, without specifying what the goods were, and that the defendent thereafter promised to pay the sum on request, etc., does not give enough information to court and opposing counsel. The difference is, presumably, between saying generally that the defendant is indebted for goods sold and delivered, or saying-as in Eng-

zo "Precedent and analogy are our only guides." Mitchell, J., in Clark v. C. M. \& St. P. Ry., 28 Minn. 69, 72, 9 N.W. 75 (I88r).

${ }_{2 x}$ Conn. Gen. Stats. I930, $\$ 5527$. 
land-that he is "indebted for butcher's meat sold and delivered, of which a detailed statement has been delivered to the defendant." ${ }_{22}$

The point is, no amount of argument about 'statements of fact' and 'conclusions of law' can possibly settle the question. Only the decision of the court of last resort or an officially adopted form (as in Connecticut and in England) can give the answer. In the absence of either of these the only guide, and not a very certain one at that, is precedent, and lacking that, analogy. It is worthy of note that the "Preliminary Draft of the Rules of Civil Procedure" for the federal courts specifically authorizes the use of the common counts. The precise language is:

A pleader may employ one or more of the appropriate so-called "common counts" subject to the power of the court to order a further statement under the provisions of Rule $x 7^{23}$

In this solution of the problem the present writer concurs. The decision, as indeed Professor Hinton pointed out in discussing the common counts in the passage quoted above, must be made on the basis of convenience, all things considered, and from that point of view there seems no real objection to their use with proper provision for a fuller statement if necessary.

It may be worth while before ending our discussion to note the language of the proposed federal rules so far as relates to the complaint. It reads:

The complaint shall be sufficient if it contain ( $x$ ) a short and plain statement of the grounds upon which the court's jurisdiction depends; (2) a short and plain statement of the claim showing that the plaintiff is entitled to relief; and (3) a demand for the relief to which he deems himself entitled.4

Note, however, that the pleaders in the federal courts are not to be left to guess as to the meaning of this language. Rule 8 reads:

The forms attached to these rules in the Appendix of Forms, with appropriate changes as circumstances may require, shall be considered sufficient under these rules.

22 In The Annual Practice 1669 (1936) the following form is approved: "The plaintiff's claim is for the price of goods sold, and delivered.

Particulars: I898-3ist December-

Balance of account for butcher's meat to this date, full particulars of which have been delivered."

And of course the "indorsements on writs of summons" are still more general, e.g., "plaintiff's claim is for $£_{50}$, for the price of goods sold."

${ }^{23}$ Rule 13 , a (6).

${ }^{24}$ The requirement that the complaint contain a statement of the claim "showing that the plaintiff is entitled to relief" is of course not to be taken literally unless it is meant to abolish all "affirmative defenses" which set forth "new matter" by way of excuse, justification, or discharge. The prior section (Rule $\mathrm{x}_{3}$ ) shows that this is not intended. 
All of which is as it should be. In no other way can useless litigation be avoided.

To sum up our argument: when ancient landmarks are swept away, they must obviously be replaced by other marks at least equally useful in guiding the wayfarer through the pleading wilderness. But, from the very nature of verbal symbols and of 'facts,' a direction to "state the facts constituting the cause of action" or to "state in plain and concise language the cause of action" can not possibly furnish adequate guidance. It can do little more than generate doubt and uncertainty and provoke controversy and litigation. That has been the uniform experience in the past. If such directions are accompanied by an adequate set of forms, which while not required are sufficient if used, the difficulty is solved and peace and good order reign in the pleader's world. ${ }^{25}$ It is to be hoped that the example now about to be set by the new federal rules will be followed by all committees which in the future may be set at the task of "simplifying pleading." ${ }_{26}$

${ }_{25}$ It is interesting to note that Professor Hinton undoubtedly realized the source of the difficulties. Thus in the lectures on the Illinois Act he called attention to the fact that the pleader under the common law system usually had little difficulty since he was supplied with a set of forms which had become recognized as sufficient. See especially the passage in Hinton, op. cit. supra note $I$, at 7 . To be sure, under that system difficulties arose when the substantive law was doubtful and the pleader was accordingly uncertain just what if any 'cause of action' his client had.

${ }^{26}$ In $x 934$ the writer was asked to aid in revising the Regulations of the U.S. Treasury Department with reference to the enrollment and disbarment of attorneys and other agents representing clients before the Department. One task was to revise the "code" of procedure before the Committee in disbarment cases. In Sec. 8 of Department Circular 230 as revised October I, I934, the following provisions as to statements of charges of misconduct were adopted:

".... statement of charges, .... giving a plain and concise description of facts which it is claimed constitute grounds for reprimand, suspension, or disbarment, without a detailed description of such facts. A statement of charges which fairly informs the respondent of the charges against him so that he is able to prepare his defense shall be deemed sufficient. Different means by which a purpose may be accomplished or different intents with which acts may be done so as to constitute ground for reprimand, suspension, or disbarment may be alleged in the statement of charges in a single count in the alternative. If, in order to prepare his defense, the respondent desires additional information as to the time and place of the alleged misconduct, or the means by which it was committed, or any other more specific information concerning the alleged misconduct, he may present a motion in writing to the Committee asking that the statement of charges be made more specific, setting forth in such motion in specific manner in what respect the statement of charges leaves him in doubt and describing the particular language of the statement of charges as to which additional information is needed. If in the opinion of the Committee such information is reasonably necessary to enable the respondent to prepare his defense, the Committee shall direct the attorney for the Government to furnish the respondent with an amended statement of charges giving the needed information." 